Check for updates

Cite this: J. Mater. Chem. B, 2020, 8, 5131

Received 26th March 2020 Accepted 25th April 2020

DOI: 10.1039/d0tb00810a

rsc.li/materials-b

\title{
Enhanced photodynamic therapy and fluorescence imaging using gold nanorods for porphyrin delivery in a novel in vitro squamous cell carcinoma 3D model $\dagger$
}

\author{
Fatma Demir Duman, (D) *ad Matej Sebek, ${ }^{\text {bc }}$ Nguyễn T. K. Thanh, (D) bc \\ Marilena Loizidou, ${ }^{a}$ Kaveh Shakib ${ }^{a}$ and Alexander J. MacRobert*a
}

\begin{abstract}
Nanocomposites of gold nanorods (Au NRs) with the cationic porphyrin TMPyP $(5,10,15,20$-tetrakis(1methyl 4-pyridinio)porphyrin tetra(p-toluenesulfonate)) were investigated as a nanocarrier system for photodynamic therapy (PDT) and fluorescence imaging. To confer biocompatibility and facilitate the cellular uptake, the NRs were encapsulated with polyacrylic acid (PAA) and efficiently loaded with the cationic porphyrin by electrostatic interaction. The nanocomposites were tested with and without light exposure following incubation in 2D monolayer cultures and a 3D compressed collagen construct of head and neck squamous cell carcinoma (HNSCC). The results showed that Au NRs enhance the absorption and emission intensity of TMPyP and improve its photodynamic efficiency and fluorescence imaging capability in both 2D cultures and 3D cancer constructs. Au NRs are promising theranostic agents for delivery of photosensitisers for HNSCC treatment and imaging.
\end{abstract}

\section{Introduction}

Head and neck cancers comprise a group of heterogeneous tumours located in various anatomical sites of the head and neck region. About $90 \%$ of these cancer types display squamous cell carcinoma histology. ${ }^{1,2}$ Each year, 500000 people are diagnosed with head and neck squamous cell carcinoma (HNSCC). This corresponds to the sixth most common cancer across the world, of which $40-50 \%$ results in death. ${ }^{3,4}$ This tumour type comprises neoplasms of the oral and nasal cavity, larynx and pharynx, and exhibits a heterogeneous and complex anatomical structure. ${ }^{5}$ The established standard treatment modalities are surgery and/or radiation therapy, combined with chemotherapy. ${ }^{6,7}$ However, ablative surgery often requires removal of functional tissues to ensure tumour-free margins

\footnotetext{
${ }^{a}$ Division of Surgery and Interventional Science, Centre for Nanomedicine and Surgical Theranostics, University College London, Royal Free Campus, Rowland Hill St, London, NW3 2PE, UK. E-mail: a.macrobert@ucl.ac.uk

${ }^{b}$ Biophysics Group, Department of Physics and Astronomy, University College London, London, WC1E 6BT, UK

${ }^{c}$ UCL Healthcare Biomagnetic and Nanomaterals Laboratories, 21 Albemarle Street, London W1S $4 B S$, UK

${ }^{d}$ WestCHEM School of Chemistry, University of Glasgow, Joseph Black Building, University Avenue, Glasgow, G12 8QQ, UK. E-mail: fatma.demirduman@glasgow.ac.uk $\dagger$ Electronic supplementary information (ESI) available. See DOI: 10.1039/ dotb00810a
}

that affect body functions including speech and swallowing. On the other hand, radiotherapy can induce major adverse events such as osteoradionecrosis, difficulty in speech and swallowing. ${ }^{8}$ Thus, there is a necessity to develop curative treatment techniques with no long-term side effects.

Photodynamic therapy (PDT) is a promising alternative treatment for precancerous and cancerous oral lesions with its minimal cumulative side effects. Its non-invasive nature has enabled the application of the technique successfully for HNSCC treatment with no adverse effects. ${ }^{8-11}$ PDT uses a photosensitizer (PS), low power, non-thermal visible light and molecular oxygen. The photosensitizer is activated upon absorption of light, which results in the generation of reactive oxygen species (ROS) such as singlet oxygen that induce cellular damage by oxidizing substrates such as aromatic amino acids and membrane components such as unsaturated fatty acid and cholesterol. For eradication of malignant, premalignant or hyperproliferative lesions, direct cellular and vascular destruction and activation of the host immune response can contribute to the mechanism of eradication. ${ }^{12-15}$

The use of metallic nanoparticles to enhance the photodynamic activity of photosensitizers by increasing singlet oxygen generation has stimulated considerable interest. ${ }^{16,17}$ Under light excitation, surface electrons of metallic nanoparticles show a collective oscillation (localized surface plasmon) that can stimulate various optical events near the surface of metallic nanoparticles such as metal enhanced singlet oxygen generation, 
surface-enhanced Raman scattering (SERS), absorption, and fluorescence and phosphorescence emission intensity. ${ }^{18,19}$ Gold nanorods (Au NRs) have attracted attention due to their high biocompatibility, stability and tunable plasmon resonance bands that enhance ROS generation for PDT applications. ${ }^{20-23}$ Ferreira and coworkers investigated gold nanostructures of spheres and rods, loading them with a photosensitizer, $5,10,15,20$-tetrakis ( $N$-methylpyridinium-4-yl)porphyrin tosylate salt, to form colloidal hybrid systems. Their studies using electron paramagnetic resonance (EPR) showed that the hybrid systems composed of Au NRs and the photosensitizer are more efficient than their free structures in terms of ROS generation, although this was not the case for spheroidal NPs. ${ }^{23}$

The therapeutic efficacy of anticancer agents has to date generally been assessed in 2 dimensional (2D) monolayer in vitro cell culture or in vivo animal models. ${ }^{24}$ However, 2D models cannot replicate interactions between the cells and the surrounding extracellular matrix (ECM) that are present with in vivo models, and the main interactions of the cells in the monolayer culture take place with the plastic surface. ${ }^{25,26}$ On the other hand, in vivo models are expensive and timeconsuming, which can decelerate the screening of new drugs and approval of new treatments. Animal studies are also subject to an increasing focus with the principles of the '3Rs' (Replacement, Reduction and Refinement), which has led to the search for alternative approaches. ${ }^{26}$ In order to overcome these problems, researchers have developed in vitro 3D culture models that mimic the microenvironmental structure of in vivo solid tumour, and bridge the gap between in vitro $2 \mathrm{D}$ findings and in vivo relevance. ${ }^{27,28} 3 \mathrm{D}$ models incorporate ECM materials such as collagen that forms a scaffold for 3D cellular organization and in vivo interactions. This structure provides a biomimetic tumour model that can recapitulate some in vivo properties such as cell differentiation, proliferation, gene and protein expression, and enable better screening for drug discovery.$^{29} \mathrm{~A}$ further key advantage that is particularly relevant to an oxygen-dependent therapy like PDT is that 3D models can incorporate the hypoxia that is often observed in solid tumours. For nanoparticle testing, 3D models also hold great promise for assessment of their therapeutic and imaging abilities including PDT particularly since they can accommodate the slower diffusion of nanoparticles through ECM compared to small molecular photosensitisers. ${ }^{29-31}$ In this regard, compressed collagen hydrogel constructs, as employed herein, exhibit near physiological collagen densities of $c a$. $10 \% \mathrm{wt} / \mathrm{wt}$ compared to $<0.5 \% \mathrm{wt} / \mathrm{wt}$ of standard uncompressed hydrogels. ${ }^{32}$

In the present work, we initially synthesized Au NRs with seed-mediated growth in the presence of a cationic surfactant, cetyltrimethylammonium bromide (CTAB), and then after coating Au NRs with an anionic polymer, polyacrylic acid (PAA), we decorated them with a positively charged, watersoluble PS, 5,10,15,20-tetrakis(1-methyl 4-pyridinio)porphyrin tetra( $p$-toluenesulfonate) (TMPyP). Porphyrins are excellent PSs with high molar absorption coefficients in the visible region, high quantum yields of the triplet state and long-lived excited states $(1 \mathrm{~s})$, low dark toxicity and fluorescence imaging properties. ${ }^{33,34}$
TMPyP has a high ${ }^{1} \mathrm{O}_{2}$ yield $\left(\phi_{\Delta}=0.77\right)$ and ROS generation ability upon light activation, which results primarily in DNA damage $^{35}$ and changes in cytoskeleton dynamics that cause microtubule disorganization and depolymerization by its ability to bind tubulin. ${ }^{36}$ The photodynamic effect of TMPyP has been shown by many groups against various human cancer cell lines including ovary, ${ }^{37}$ colon, ${ }^{38,39}$ lungs, ${ }^{37}$ cervix, ${ }^{36,40}$ breast, ${ }^{37,41}$ leukemia, ${ }^{35}$ melanoma, ${ }^{36,41}$ and larynx. ${ }^{42}$ This PS has also been investigated for other biomedical applications including sensing, detection and imaging. ${ }^{43-46}$

The prepared structures were characterized by using absorbance and fluorescence spectroscopy, transmission electron microscopy (TEM), dynamic light scattering (DLS) and zeta potential analysis. The dark toxicity and PDT effects were compared with Au NRs without PAA coating and free TMPyP in 2D monolayer cancer models and $3 \mathrm{D}$ compressed collagen constructs of A431 human squamous carcinoma. The hybrid structures were also evaluated as optical cancer imaging agents owing to the emission of TMPyP in the red and near-infrared regions of the optical spectrum.

\section{Materials and methods}

\subsection{Materials}

The following products were used as received. Gold(III) chloride trihydrate $\left(\mathrm{HAuCl}_{4} \cdot 3 \mathrm{H}_{2} \mathrm{O}, \geq 99.9 \%\right.$ trace metal basis), sodium borohydride $\left(\mathrm{NaBH}_{4}, 98 \%\right)$, sodium bromide $(\mathrm{NaBr}, \geq 99.0 \%)$, sodium chloride ( $\mathrm{NaCl}, \geq 99.5 \%)$, L-ascorbic acid (99\%), silver nitrate $\left(\mathrm{AgNO}_{3}, 0.1 \mathrm{~N}\right)$, hydrogen chloride $(\mathrm{HCl}, 37 \mathrm{wt} \%$ in water), poly(acrylic acid, sodium salt) solution (PAA, average MW 15000, $35 \mathrm{wt} \%$ in water), 5,10,15,20-tetrakis(1-methyl 4-pyridinio)porphyrin tetra( $p$-toluenesulfonate) (TMPyP), thiazolyl blue tetrazolium bromide (MTT, 98\%), bovine serum albumin, Triton ${ }^{\mathrm{TM}} \mathrm{X}-100$, phosphate buffered saline (PBS), Dulbecco's phosphate-buffered saline (modified, without calcium chloride and magnesium chloride, liquid) and 96-well plates (Corning ${ }^{\mathbb{R}}$ TC-treated, clear, polystyrene, flat bottom) were purchased from Sigma-Aldrich (UK). CTAB (>98\%) was obtained from Tokyo Chemical Industry (TCI, Japan). Minimum essential medium (MEM $(10 \times$, no glutamine), 4-(2-hydroxyethyl)1-piperazineethanesulfonic acid (HEPES) buffer solution (1 M), penicillin-streptomycin and trypsin-ethylenediaminetetraacetic acid (trypsin-EDTA) $(1 \times, 0.25 \%)$ were purchased from Gibco (UK). MEM with Earle's Balanced Salt Solution (EBSS, without L-glutamine) was provided by Fisher Scientific Ltd (UK). Rat tail collagen (Type I) was purchased from First Link Ltd (Cat \#: 60-30810, UK). Alexa Fluor ${ }^{\mathrm{TM}} 488$ Phalloidin and AlamarBlue cell viability reagent were purchased from Invitrogen (UK). VECTASHIELD $^{\circledR}$ antifade mounting medium with 4 $^{\prime}$,6-diamidino2-phenylindole (DAPI) was obtained from Vector Labs (UK). Black 96-well plates (polypropylene, F-bottom, chimney) were purchased from Greiner Bio-One International (UK). Glass bottomed tissue culture dishes (Fluorodish Cell Culture Dish $35 \mathrm{~mm}$ ) were purchased from World Precision Instruments (UK). 
Ultra-pure water $(18.2 \mathrm{M} \Omega \mathrm{cm})$ was used in all experiments (Milli-Q Integral 5 system, Merck Millipore, USA).

\subsection{Synthesis of AuNRs}

Au NRs were synthesized via the seed-mediated method according to the previous reports with slight modifications. ${ }^{47,48}$

Synthesis of Au seeds. The reaction was performed at $25{ }^{\circ} \mathrm{C}$. $5 \mathrm{~mL}$ of a solution of $\mathrm{HAuCl}_{4}(1 \mathrm{mM})$ was added to the completely dissolved CTAB solution $(5 \mathrm{~mL}, 0.2 \mathrm{M}) .0 .8 \mathrm{~mL}$ of ice-cold $\mathrm{NaBH}_{4}(10 \mathrm{mM})$ was added at once into this mixture under vigorous stirring. The solution was stirred for $30 \mathrm{~s}$ and kept undisturbed for $1 \mathrm{~h}$ at $25{ }^{\circ} \mathrm{C}$. Then, the seed solution was immediately used for gold nanorod synthesis.

Synthesis of Au NRs. $205 \mu \mathrm{L}$ of $\mathrm{AgNO}_{3}(4 \mathrm{mM})$ was added into $5 \mathrm{~mL}$ of completely dissolved CTAB solution $(0.1 \mathrm{M})$ and kept undisturbed for $15 \mathrm{~min}$ at $25{ }^{\circ} \mathrm{C} . \mathrm{HAuCl}_{4}(5 \mathrm{~mL}, 1 \mathrm{mM}), \mathrm{NaBr}$ $(396 \mu \mathrm{L}, 0.52 \mathrm{M})$ and $\mathrm{HCl}(12 \mu \mathrm{L}, 37 \%)$ were subsequently introduced into this mixture, respectively, and stirred slowly. The mixture was vigorously stirred for $30 \mathrm{~s}$ after addition of $75 \mu \mathrm{L}$ of ascorbic acid $(79 \mathrm{mM})$. Finally, $60 \mu \mathrm{L}$ of the seed solution was added into the growth solution at once and $30 \mathrm{~s}$ vigorous stirring was performed one more time. The solution was left undisturbed at $25{ }^{\circ} \mathrm{C}$ overnight (12-16 h). The Au NRs were washed by centrifugation twice at $8500 \mathrm{rpm}$ for $15 \mathrm{~min}$ and the pellet was re-suspended in $4 \mathrm{~mL}$ of deionized water for further studies.

\subsection{PAA coating of Au NRs}

The Au NRs were then electrostatically coated with PAA polymer $(\sim 15 \mathrm{kDa} \mathrm{MW})$ at $25{ }^{\circ} \mathrm{C}$. PAA solution $\left(100 \mu \mathrm{L}, 10 \mathrm{mg} \mathrm{mL} \mathrm{m}^{-1}\right.$ prepared in $10 \mathrm{mM} \mathrm{NaCl}$ solution) and $\mathrm{NaCl}$ solution $(100 \mu \mathrm{L}$, $10 \mathrm{mM}$ ) were simultaneously added to $1 \mathrm{~mL}$ of $\mathrm{Au}$ NR solution $\left(1.12 \mathrm{mg} \mathrm{mL}^{-1}\right)$. The solution was stirred gently for $30 \mathrm{~min}$ to achieve complete polymer coating. To remove excess PAA, the resulting solution was centrifuged for $3 \mathrm{~min}$ at $14000 \mathrm{rpm}(\times 1)$ and the pellet was re-suspended in deionized water. ${ }^{49}$

\subsection{Cationic porphyrin loading of PAA-Au NRs}

A $0.47 \mathrm{mg} \mathrm{mL}{ }^{-1}$ aqueous solution of PAA-Au NRs was mixed with the cationic porphyrin TMPyP at different concentrations and stirred for $15 \mathrm{~min}$ at room temperature for electrostatic binding of the porphyrin with the NRs.

\subsection{Characterization methods}

Absorbance and fluorescence measurements were recorded using a Spectramax $\mathrm{M} 2 / \mathrm{M} 2{ }^{\mathrm{e}} \mathrm{UV} / \mathrm{Vis} / \mathrm{NIR}$ spectrophotometer. The hydrodynamic size and $\zeta$ potential of the particles were determined with a Malvern Zetasizer Nano-Z. TEM images were obtained using a JEM-2100 microscope operating at $200 \mathrm{kV}$. Aqueous solutions of Au NRs were dropped on a carbon-coated $\mathrm{Cu}$-grid and dried for TEM imaging analysis. $\mathrm{pH}$ measurements were performed using an Orion Star A111 Benchtop meter from Thermo Scientific. Fluorescence spectroscopic measurements in cells were performed using a fluorescence plate reader (Fluoroskan Ascent, Thermo Labsystems).

\subsection{Cell culture}

A431 human squamous carcinoma cells were purchased from Sigma (\# 85090402) and were cultured in MEM supplemented with $10 \%$ FBS, 1\% penicillin-streptomycin (10 000 units per ml and $10000 \mu \mathrm{g} \mathrm{ml}^{-1}$, respectively), $2 \mathrm{mM}$ glutamine and $1 \%$ nonessential amino acid solution, and grown in a humidified incubator at $37{ }^{\circ} \mathrm{C}$ under $5 \% \mathrm{CO}_{2}$.

\subsection{In vitro dark toxicity and phototoxicity studies on $2 \mathrm{D}$ monolayer HNSCC models}

Dark toxicity. A431 cells were seeded at a density of 7500 cells per well into 96-well plates and incubated at $37{ }^{\circ} \mathrm{C}$ in a $5 \% \mathrm{CO}_{2}$ atmosphere. On the second day, the cells were treated with Au NRs, PAA-Au NRs, PAA-Au NR + TMPyP and free cationic porphyrin TMPyP in different concentrations in serum-free medium and incubated for an additional $24 \mathrm{~h}$ at $37{ }^{\circ} \mathrm{C}$ in a $5 \% \mathrm{CO}_{2}$ atmosphere. On the third day, the culture medium in each well was replaced with serum-containing medium without NR and TMPyP photosensitizer, and incubated for another $24 \mathrm{~h}$. On the fourth day, the cytotoxicity was measured by MTT assay. $25 \mu \mathrm{L}$ of MTT solution $\left(5 \mathrm{mg} \mathrm{mL}^{-1}\right.$ in PBS) was added to each well with $75 \mu \mathrm{L}$ of culture medium and incubated for 4 more hours. DMSO/EtOH (1:1 v/v) solution was used to dissolve purple formazan crystals that appear in the mitochondria of the living cells and the absorbance intensity was measured at $570 \mathrm{~nm}$ using a microplate reader (Fluoroskan Ascent, Thermo Labsystems). The percent cell viability was calculated in reference to the untreated control cells using the following formula:

$$
\text { Cell viability }(\%)=\left[\frac{\text { sample absorbance }}{\text { control absorbance }}\right] \times 100 \quad(n=5)
$$

PDT phototoxicity. A431 cells were seeded and treated with samples as in the dark toxicity studies. On the third day, after replacement of the medium, the plates were illuminated with light for up to $10 \mathrm{~min}$ using a blue LumiSource ${ }^{\circledR}$ flatbed lamp with peak emission at $420 \mathrm{~nm}$ and $7 \mathrm{~mW} \mathrm{~cm}^{-2}$ output (PCI Biotech, Oslo, Norway). The illuminated cells were incubated for an additional $24 \mathrm{~h}$ at $37{ }^{\circ} \mathrm{C}$ in $5 \% \mathrm{CO}_{2}$ and cell viability was assessed by MTT assay on the fourth day as described previously. The cells without treatment with samples were considered as controls. The untreated control cells without sample were also studied with and without light exposure.

\subsection{Fluorescence measurements on 2D monolayer HNSCC models}

Fluorescence detection of the nanocomposites of $\mathrm{Au}$ NRs, PAA-Au NRs, PAA-Au NR + TMPyP and free cationic porphyrin TMPyP treated 2D monolayer A431 cancer models was performed using an inverted fluorescence microscope and a fluorescence plate reader. To prepare 2D monolayer A431 cancer models for fluorescence imaging, on the first day, A431 cells were seeded at a density of 150000 cells in a glass bottom tissue culture dish and incubated for $24 \mathrm{~h}$ under 
standard culture conditions. On the second day, they were incubated with the samples at $20 \mu \mathrm{g} \mathrm{mL}{ }^{-1} \mathrm{NRs}$ and $1.08 \mu \mathrm{g} \mathrm{mL}$ equivalent TMPyP concentration of PAA-Au NRs + TMPyP in serumfree medium. After $24 \mathrm{~h}$ of incubation with the samples, 2D monolayer models were washed with PBS, fixed with formalin for $20 \mathrm{~min}$ at room temperature, stained with DAPI nuclei dye for $10 \mathrm{~min}\left(2 \mu \mathrm{g} \mathrm{mL}{ }^{-1}\right)$, and finally left in $1 \mathrm{~mL}$ of PBS to keep the cells from air drying. The fixed cells were visualized using an inverted fluorescence microscope (Olympus BX63; Olympus, Tokyo, Japan) using filters for DAPI $(\mathrm{Ex} / \mathrm{Em}=360 / 460 \mathrm{~nm})$ and TMPyP (Cy5: Exc/ $\mathrm{Em}=620 / 700 \mathrm{~nm})$, respectively.

For a quantitative measurement of the fluorescence intensity by using a fluorescence plate reader, A431 cells were seeded at a density of 7500 cells per well into 96-well plates and incubated for $24 \mathrm{~h}$ under standard culture conditions. The samples were then incubated with the cells at different concentrations in serum-free medium and incubated for $24 \mathrm{~h}$. On the third day, the cells in each well were washed with PBS $(3 \times)$, left in $0.2 \mathrm{~mL}$ of PBS, and then the fluorescence intensities were recorded between 600 and $750 \mathrm{~nm}$ using a fluorescence plate reader (Fluoroskan Ascent, Thermo Labsystems) and excitation at $420 \mathrm{~nm}$.

\subsection{Manufacture of 3D compressed HNSCC collagen constructs}

The 3D compressed collagen constructs of A431 human squamous carcinoma were prepared using RAFT 3D culture systems following the manufacturer's instructions (Lonza, Slough, UK) and the procedure of Hadi et al. ${ }^{32,50,51}$ In brief, 10\% 10× MEM (employed as colour/pH indicator) and $80 \%$ Rat Tail Collagen Type I were mixed and neutralized using a solution prepared from $1.65 \mathrm{M} \mathrm{NaOH}$ and $840 \mathrm{mM}$ HEPES buffer solution for hydrogel formation. A431 cells were seeded into this collagen hydrogel structure at a density of 50000 cells and the obtained collagen-MEM-cell solution was aliquoted into the 96-well plate ( $240 \mu \mathrm{L}$ per well) after being mixed gently. The constructs were incubated under standard culture conditions for $15 \mathrm{~min}$ to initiate collagen fibrillogenesis and produce a cell-populated collagen hydrogel. The collagen constructs were subjected to plastic compression using hydrophilic RAFT ${ }^{\mathrm{TM}}$ absorbers placed on the hydrogels and left for $15 \mathrm{~min}$ at room temperature. Finally, the absorbers were removed and the cells were returned to the incubator at $37{ }^{\circ} \mathrm{C}$ under $5 \% \mathrm{CO}_{2}$, after addition of fresh culture medium to each well.

\subsection{Imaging of 3D compressed HNSCC collagen constructs}

Cell morphology and spheroid formation in 3D cancer constructs were investigated at different time points (days 1, 3, 7

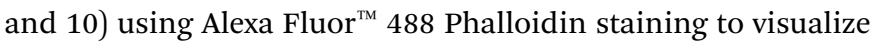
filamentous actin, and DAPI dye for imaging of cell nuclei following initial cell seeding. To prepare the constructs for imaging, they were fixed with $10 \%$ formalin for $30 \mathrm{~min}$ and washed with PBS. Then, they were permeabilised with $1 \%$ bovine serum albumin (BSA) and $0.3 \%$ Triton $\mathrm{X}$ solution for $1 \mathrm{~h}$, stained with Phalloidin (2.5\% in BSA/Triton-X solution) for $1.5 \mathrm{~h}$ and washed with PBS $(3 \times)$. The constructs were placed on a slide and treated with one drop of VECTASHIELD ${ }^{\circledR}$ antifade mounting medium with DAPI and covered with a cover slip. Then, they were imaged using an Olympus BX63 inverted fluorescence microscope equipped with filters for DAPI $(\mathrm{Exc} / \mathrm{Em}=360 / 460 \mathrm{~nm})$ and Alexa Fluor 488 labelled Phalloidin $(\mathrm{Exc} / \mathrm{Em}=495 / 525 \mathrm{~nm})$, respectively.

\subsection{In vitro dark toxicity and PDT phototoxicity studies on 3D compressed HNSCC collagen constructs}

The early model of 3D compressed collagen constructs prepared by RAFT $^{\mathrm{TM}}$ 3D culture systems (1 day growth) were incubated with Au NRs, PAA-Au NRs, PAA-Au NRs + TMPyP and free TMPyP at $20 \mu \mathrm{g} \mathrm{mL} \mathrm{m}^{-1} \mathrm{NRs}, 1.08 \mu \mathrm{g} \mathrm{mL} \mathrm{m}^{-1}$ equivalent TMPyP concentration of PAA-Au NRs + TMPyP in serum-free medium for $24 \mathrm{~h}$. On the next day, the medium of each construct was replaced with serum-containing medium without NRs and photosensitizer. To assess the dark toxicity of the samples in the 3D compressed collagen constructs of A431, the $3 \mathrm{D}$ structures were directly returned to the incubator for another $24 \mathrm{~h}$ of incubation. To assess the PDT effect of TMPyP loaded PAA-Au NRs, the constructs were illuminated with a blue LumiSource $^{\mathbb{R}}$ flatbed lamp with peak emission at $420 \mathrm{~nm}$ and $7 \mathrm{~mW} \mathrm{~cm} \mathrm{~cm}^{-2}$ output (PCI Biotech, Oslo, Norway) for $7 \mathrm{~min}$ and $20 \mathrm{~min}$ and then returned to the incubator. After $24 \mathrm{~h}$, both dark toxicity and phototoxicity of $3 \mathrm{D}$ constructs were evaluated by Alamar Blue assay according to the manufacturer's instructions. Alamar Blue solution was added to each well as $10 \%$ of the culture medium and incubated at $37{ }^{\circ} \mathrm{C}$ in $5 \% \mathrm{CO}_{2}$ for $4 \mathrm{~h}$. Then, the supernatant in each well was transferred into 96-well black plates. Fluorescence measurements were recorded under $560 \mathrm{~nm}$ excitation and $590 \mathrm{~nm}$ emission using a fluorescence plate reader (Fluoroskan Ascent, Thermo Labsystems). The constructs without treatment with the samples were used as controls. The percentage cell viability was calculated by comparing the fluorescence intensities of each construct to the fluorescence in the untreated cells.

\subsection{Imaging of 3D compressed HNSCC collagen constructs using cationic porphyrin loaded Au NRs}

The fluorescence images of Au NRs, PAA-Au NRs, PAA-Au NRs + TMPyP and free TMPyP treated 3D compressed head and neck squamous cancer collagen constructs were recorded using an inverted fluorescence microscope. The early models of $3 \mathrm{D}$ compressed collagen constructs were incubated with the samples at $20 \mu \mathrm{g} \mathrm{mL}^{-1} \mathrm{NRs}, 1.08 \mu \mathrm{g} \mathrm{mL}^{-1} \mathrm{TMPyP}$ concentration and incubated for a further $24 \mathrm{~h}$ at $37{ }^{\circ} \mathrm{C}$ in $5 \% \mathrm{CO}_{2}$. Afterwards, $3 \mathrm{D}$ constructs were washed with PBS $(3 \times)$, fixed with $10 \%$ formalin (30 min), and permeabilised with 1\% BSA and $0.3 \%$ Triton $\mathrm{X}$ solution $(1 \mathrm{~h})$. They were washed with PBS $(3 \times)$ between each step. The constructs were placed on a slide and covered with a cover slip after placing one drop of VECTASHIELD $^{\circledR}$ antifade mounting medium containing DAPI. The prepared constructs were imaged using an Olympus BX63 inverted fluorescence microscope equipped with filters for DAPI $(\mathrm{Ex} / \mathrm{Em}=360 / 460 \mathrm{~nm})$ and TMPyP $(\mathrm{Cy} 5: \mathrm{Exc} / \mathrm{Em}=$ $649 / 670 \mathrm{~nm})$, respectively. 


\subsection{Statistical analysis}

Statistical evaluation of data was carried out using one-way analysis of variance (ANOVA) followed by post hoc Tukey's Multiple Comparison Test, using Graph Pad Prism software program version 6 . Only a $p$-value $<0.05$ was considered as statistically significant. All quantitative data were presented as mean values \pm standard deviation (SD).

\section{Results and discussion}

Au NRs are capable of delivering high payloads of therapeutic agents with their large surface area-to-volume ratio. ${ }^{52-54} \mathrm{~A}$ higher uptake of the NRs in tumour compared to adjacent normal tissue is facilitated by the enhanced permeability and retention (EPR) effect. Therefore, Au NRs are applicable to the focal treatment of cancer including photodynamic and/or photothermal therapy. ${ }^{55}$ In this study, we loaded Au NRs with a cationic photosensitizer, TMPyP, to increase the photodynamic effect of the photosensitizer and use the hybrid structures as cancer imaging agents on 2D monolayer and 3D compressed collagen constructs of HNSCC, which is one of the most common cancers worldwide.

\subsection{Preparation of cationic porphyrin loaded Au NRs}

In this study, Au NRs were synthesized using seed-mediated growth in two steps. In the first step (seed), the seeds were prepared in a cationic surfactant CTAB dissolved aqueous solution. In the second step (growth), these seeds were added to a solution including $\mathrm{CTAB}$ in which more $\mathrm{HAuCl}_{4}$ is reduced by L-ascorbic acid. CTAB added in the growth step achieves the direct growth of the seeds along one axis forming rods. ${ }^{47,48,56}$ $\mathrm{Au}$ NRs show two characteristic bands in the absorption spectrum (Fig. 1A). The lower peak at $511 \mathrm{~nm}$ represents the surface plasmon resonance along the transverse direction. The second dominant peak at $818 \mathrm{~nm}$ originates from the surface plasmon along the longitudinal direction. As observed in TEM pictures in Fig. S1A (ESI $\dagger$ ), the average rod dimensions are $29.6 \pm 8.1 \mathrm{~nm}$ in length and $6.4 \pm 1.4 \mathrm{~nm}$ in width. However, CTAB is a well-known toxic cationic surfactant and Au NRs prepared by CTAB demonstrate toxicity. ${ }^{57}$ To reduce the cytotoxicity of CTAB and facilitate the cellular uptake of Au NRs, we coated Au NRs with anionic PAA by layer-by-layer adsorption, as shown in Scheme $1 .{ }^{49}$ After coating, the zeta potential of the Au NRs changed from a positive charge $(45.6 \pm 3.4 \mathrm{mV})$ to a highly negative charge $(-56.4 \pm 0.6 \mathrm{mV})$ with an increase in their hydrodynamic size from $39.2 \pm 0.6 \mathrm{~nm}$ to $54.0 \pm 1.5 \mathrm{~nm}$ (Table 1) and with no change in surface plasmon resonance peaks (Fig. 1A). The hydrodynamic diameter measured by DLS of rod-like Au NRs is not precise since a spherical model is used to calculate the data. Nonetheless, it is still useful to demonstrate the tendency of size change of the nanorods before and after any surface modification. ${ }^{58-61}$ The TEM image presented in Fig. S1B (ESI $\dagger$ ) showed that PAA coating did not seem to make the rods aggregate.

The prepared PAA-Au NRs were then loaded with a cationic photosensitizer, TMPyP, by the layer-by-layer technique (Scheme 1). The anionic surface of PAA-Au NRs was electrostatically coated with TMPyP at different concentrations of $0.0125-0.050 \mathrm{mg} \mathrm{mL} \mathrm{m}^{-1}$ to find the optimal loading of the photosensitizer. The results indicated that the decoration of PAA-Au NRs with TMPyP increases both their hydrodynamic size and surface charge (Table 1). The increase in hydrodynamic diameter in water is probably a result of the aggregation of the particles through $\pi$ to $\pi$ stacking and hydrophobic interactions as a result of the increased concentration of porphyrin-based photosynthesizer TMPyP on the nanorod structures. Gong et al. reported that since porphyrin structures have hydrophobic pyrrole subunits, hydrophobic interactions and $\pi$ to $\pi$ interaction between adjacent porphyrin macrocycles will be the dominant factors leading to nanoparticle aggregation in aqueous solution in spite of substitution to the
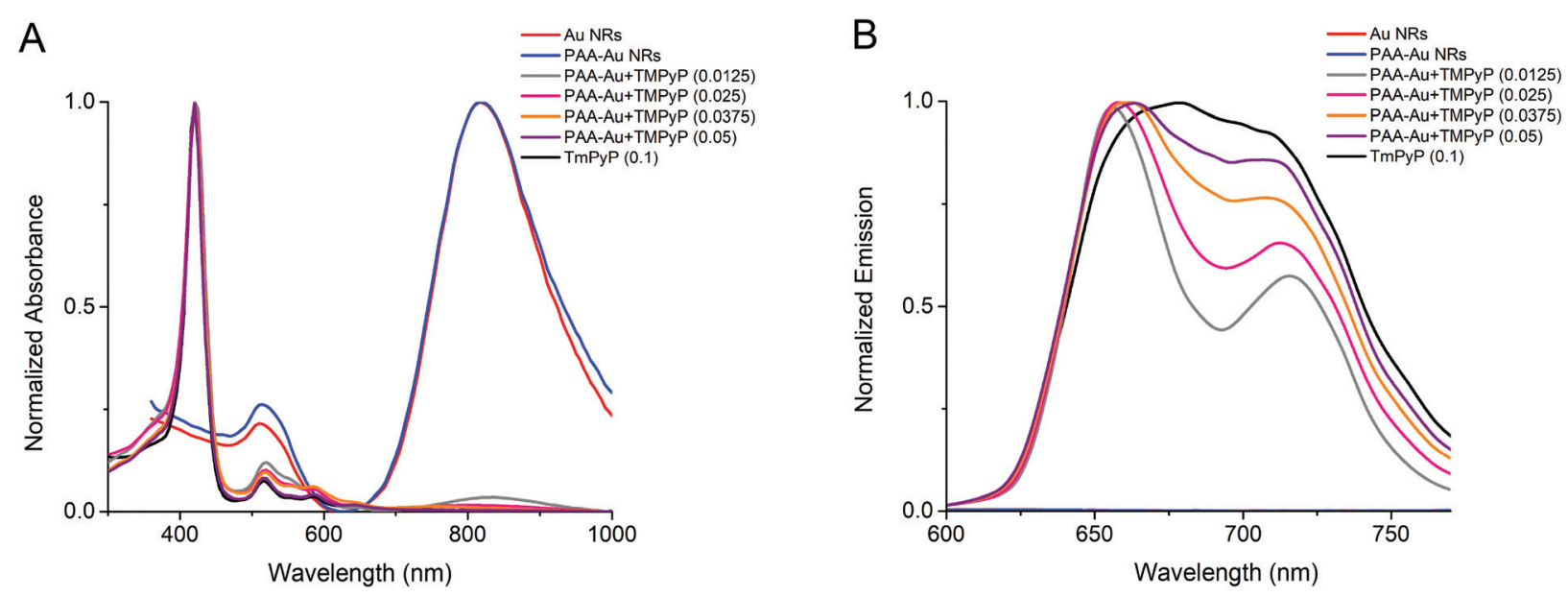

Fig. 1 Spectroscopic evaluation of Au NRs, PAA-Au NRs, PAA-Au NRs + TMPyP and free TMPyP in aqueous solutions. Normalized absorbance (A) and normalized emission spectra (B). The numbers in the parentheses imply $\mathrm{mg} \mathrm{mL}^{-1}$ TMPyP concentration used for the loading. The concentration of PAAAu NR is fixed to $0.47 \mathrm{mg} \mathrm{mL}^{-1}$ in the TMPyP loaded PAA-Au NR solutions. The concentration of the naked Au NR solution is $0.26 \mathrm{mg} \mathrm{mL}^{-1}$, that of PAA$\mathrm{Au}$ NR is $0.70 \mathrm{mg} \mathrm{mL}^{-1}$, and that of free TMPyP is $0.1 \mathrm{mg} \mathrm{mL}^{-1}\left(\lambda_{\text {exc }}=420 \mathrm{~nm}\right)$. 


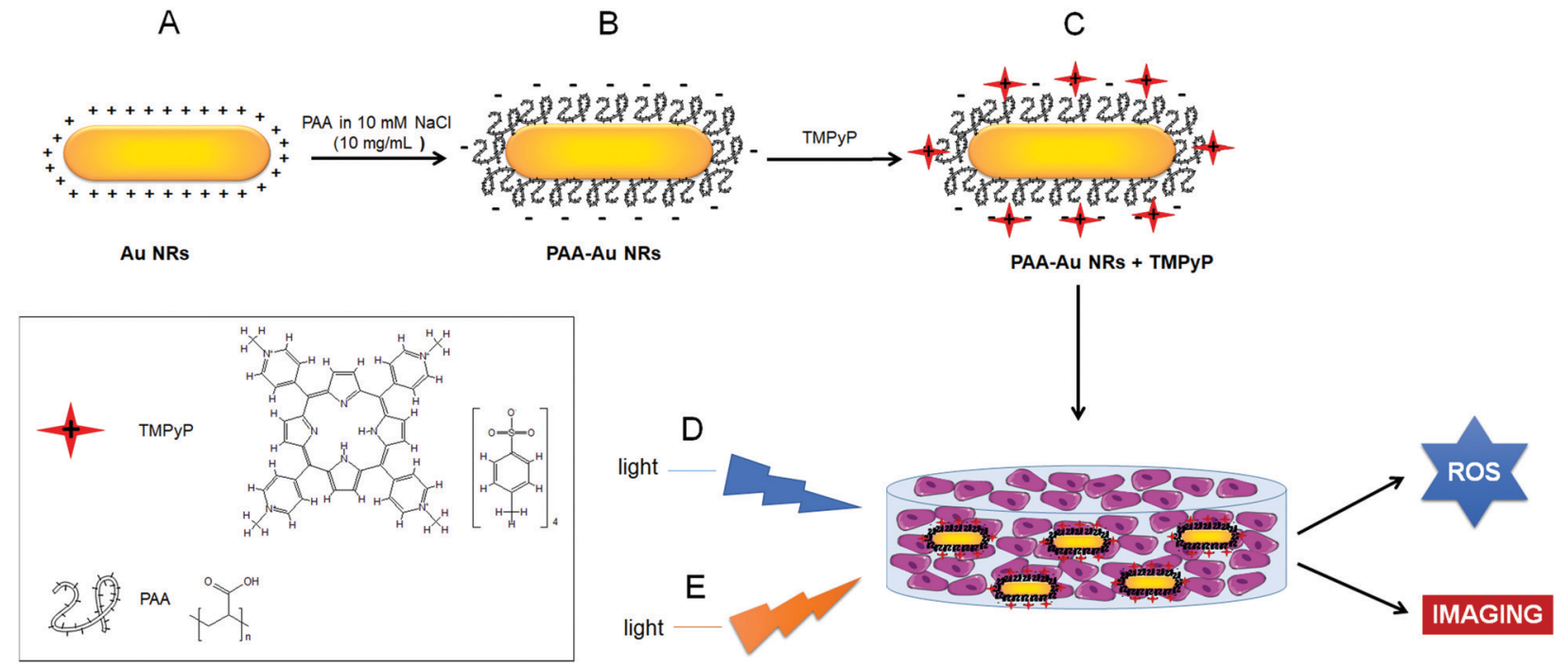

Scheme 1 Preparation of photosensitizer loaded PAA coated Au NRs and their application as a PDT agent in a 3D hydrogel model consisting of A431 cancer cells surrounded by a type 1 rat tail collagen matrix under irradiation with light. (A) Au NRs synthesized by seed-mediated growth. (B) PAA-Au NRs prepared by PAA coating of Au NRs in $10 \mathrm{mM} \mathrm{NaCl}$ solution. (C) TMPyP loading of PAA-Au NRs under aqueous conditions electrostatically. (D) Irradiation of the 3D compressed collagen constructs of A431 human squamous carcinoma incubated with PAA-Au NRs + TMPyP with blue light and ROS generation. (E) Irradiation of the 3D constructs by orange light and fluorescence imaging.

Table 1 Hydrodynamic diameters reported as intensity average and corresponding polydispersity index (PDI) and zeta potential values of $\mathrm{Au}$ NRs, PAA-Au NRs, PAA-Au NRs + TMPyP and free TMPyP in aqueous solutions. The numbers in the parentheses imply $\mathrm{mg} \mathrm{mL}^{-1} \mathrm{TMPyP}$ concentration used for the loading

\begin{tabular}{lrlr}
\hline Sample & \multicolumn{1}{l}{ Zeta potential } \\
\hline Au NRs & $39.2 \pm 0.6$ & $0.534 \pm 0.003$ & $45.6 \pm 3.4$ \\
PAA-Au NRs & $54.0 \pm 1.5$ & $0.540 \pm 0.035$ & $-56.4 \pm 0.6$ \\
PAA-Au + TMPyP (0.0125) & $111.8 \pm 4.3$ & $0.578 \pm 0.051$ & $-48.9 \pm 4.1$ \\
PAA-Au + TMPyP (0.025) & $113.1 \pm 2.4$ & $0.261 \pm 0.007$ & $-10.6 \pm 1.3$ \\
PAA-Au + TMPyP (0.0375) & $148.1 \pm 1.9$ & $0.117 \pm 0.013$ & $-10.6 \pm 0.1$ \\
PAA-Au + TMPyP (0.050) & $358.3 \pm 8.7$ & $0.214 \pm 0.015$ & $-7.5 \pm 0.4$
\end{tabular}

porphyrin structure. ${ }^{62}$ This effect has been reported in other studies, where incorporation of the photosynthesizer to the particles causes an increase in hydrodynamic size not only due to the volume of the photosynthesizer but also due to the increased aggregation of the particles under aqueous conditions as a result of the interactions of the pyrrole subunits. ${ }^{63-65}$ These factors imply an efficient interaction between anionic PAA-Au NRs and the cationic photosensitizer TMPyP. However, the zeta potential remained quite stable at the $0.025 \mathrm{mg} \mathrm{mL}^{-1}$ concentration of TMPyP while the hydrodynamic size continued to increase. To keep the size minimum for biomedical applications, we decided to use the TMPyP concentration of $0.025 \mathrm{mg} \mathrm{mL}^{-1}$ in PAA-Au NR solution having a $0.47 \mathrm{mg} \mathrm{mL}^{-1}$ nanorod concentration.

The absorption spectrum of a typical porphyrin consists of a strong peak at about $400 \mathrm{~nm}$ (Soret band), followed by several weaker absorptions ( $\mathrm{Q}$ band) at higher wavelengths (at about 515, 585 and $640 \mathrm{~nm}$ ). As shown in Fig. 1A, the TMPyP loaded PAA-Au NRs show these characteristic peaks that confirm the successful incorporation of the photosensitizer with PAA-Au NRs. In addition, porphyrins possess red or near-infrared fluorescence under excitation of visible light, which allows the diagnostic fluorescence imaging applications by visualization of intracellular localization of photosensitizers, and makes them favourable theranostic agent besides the photodynamic therapy. ${ }^{66,67}$ TMPyP loaded PAA-Au NRs maintain the characteristic emission peaks of the photosensitizer, as seen from the emission spectra of PAA-Au NRs loaded with TMPyP in different concentrations (Fig. 1B), while Au NRs and PAA-Au NRs do not show any fluorescence, hence they have no signal $\left(\lambda_{\mathrm{exc}}=\right.$ $420 \mathrm{~nm}$ ). This highlights their possible applications as fluorescence imaging agents.

\subsection{In vitro dark toxicity and phototoxicity studies on $2 \mathrm{D}$ monolayer HNSCC models}

To understand the dark toxicities and PDT effects of the prepared Au NRs, PAA-Au NRs, TMPyP loaded PAA-Au NRs (PAA-Au NRs + TMPyP) and free TMPyP, they were incubated on 2D in vitro monolayer models of A431 HNSCC without irradiation conditions. As shown in Fig. 2A, Au NRs possess high cytotoxicity even at the lowest concentrations due to CTAB coating. CTAB is a cationic surfactant that can enter cells with or without $\mathrm{Au}$ NRs, damage mitochondria, and induce apoptosis. ${ }^{68}$ To overcome this problem, we coated the Au NR surface with an anionic biocompatible polymer, PAA. As shown in the graph, the surface chemistry has a dominant role in the cytotoxicity. The cell viability increased dramatically after the incorporation of PAA as a surface coating as well as functionalizing the surfaces of NRs for further applications as it allowed here the loading of photosensitizer TMPyP electrostatically. Free TMPyP and PAA-Au NRs + TMPyP do not exhibit any significant dark cytotoxicity. This shows that they do not have 

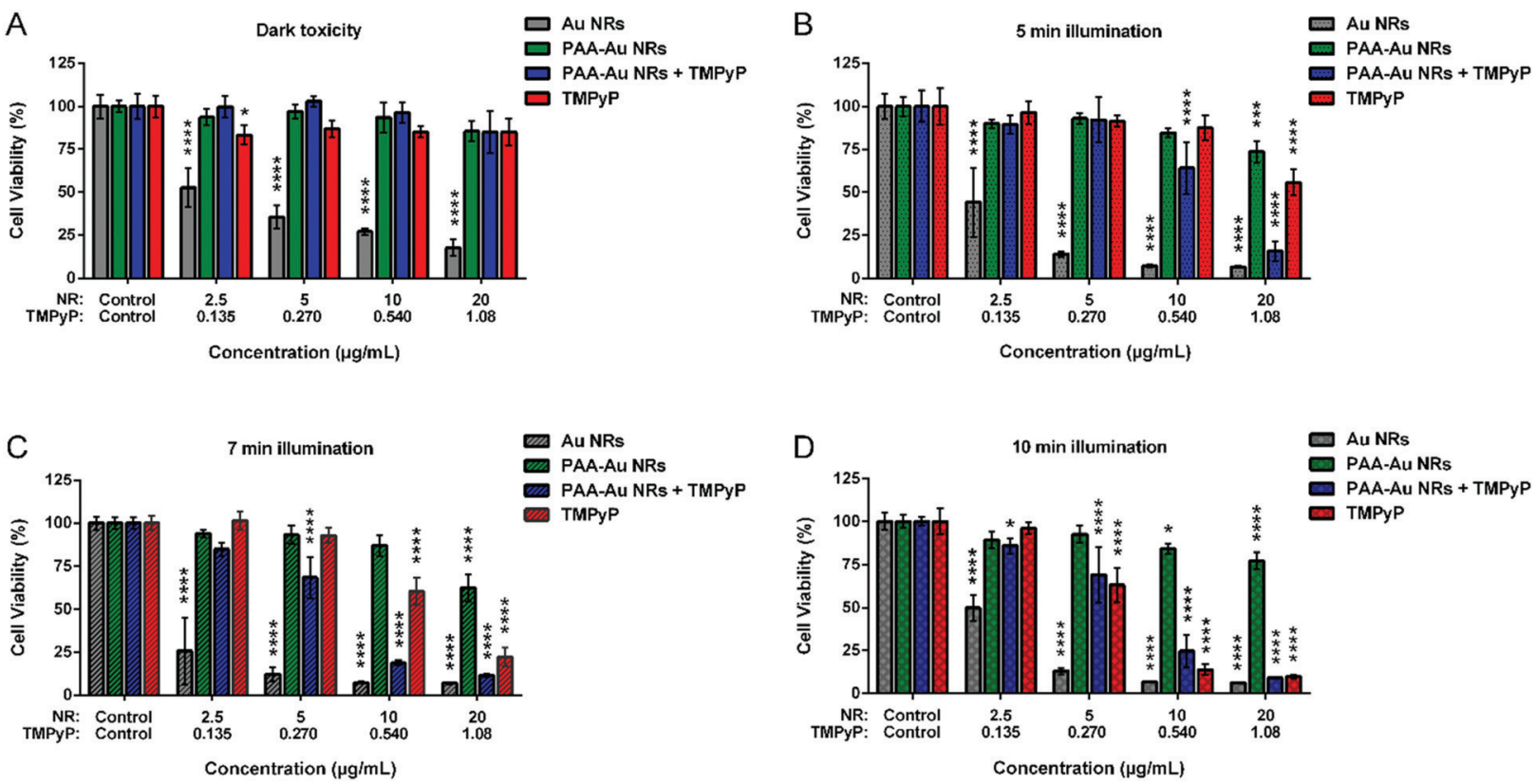

Fig. 2 Dark toxicity and phototoxicities of Au, PAA-Au, TMPyP loaded PAA-Au NRs and free TMPyP on in vitro 2D monolayer HNSCC models measured by MTT assay. (A) Dark toxicities at $48 \mathrm{~h}$ incubation. (B) Cell viability under light illumination with a blue LumiSource ${ }^{\circledR}$ flatbed lamp at $420 \mathrm{~nm}$ and $7 \mathrm{~mW} \mathrm{~cm}{ }^{-2}$ output for $5 \mathrm{~min}$, (C) $7 \mathrm{~min}$, and (D) $10 \mathrm{~min}$ at $24 \mathrm{~h}$ incubation and additional $24 \mathrm{~h}$ incubation post illumination.

any significant intrinsic toxicity (i.e., dark toxicity) without light irradiation during administration.

To evaluate the PDT potential of the samples, the in vitro $2 \mathrm{D}$ monolayer A431 cells incubated with the components were illuminated using a blue LumiSource ${ }^{\circledR}$ flatbed lamp at $420 \mathrm{~nm}$ and $7 \mathrm{~mW} \mathrm{~cm} \mathrm{~cm}^{-2}$ output for $5 \mathrm{~min}, 7 \mathrm{~min}$ and $10 \mathrm{~min}$. To understand the effect of light illumination on cell growth, cells without any sample treatment were illuminated under the same conditions and their cell viability was compared with that of the nonilluminated cells. As can be seen in Fig. S2 (ESI $\dagger$ ), the light illumination does not have any effect on the cell viability. The results represented in Fig. 2 indicate that use of Au NRs as a carrier system enhances the photodynamic effect of the photosensitizer. In particular, at $5 \mathrm{~min}$ illumination, the difference between the therapeutic effect of PAA-Au NRs + TMPyP and free TMPyP is clearly evident. This effect can be due to the enhanced localized electric field surrounding Au NRs, hence inducing an increase in light absorption of the photosensitizers and in singlet oxygen formation via energy transfer from the excited photosensitizer to molecular oxygen. ${ }^{23}$ At longer illumination times, the cytotoxic effect of free TMPyP is more apparent. Another important point is that naked Au NRs and PAA-Au NRs also exhibited phototoxicity with light illumination as compared to their dark toxicity (Fig. S4, ESI $\dagger$ ). This effect of Au NRs is due to their ROS generation under light irradiation like organic dye photosensitizers. ${ }^{23}$ Similar effects were reported with Au NRs embedded with a photosensitizing dye (crystal violet) in a polyurethane matrix to create ROS, with bactericidal activity. ${ }^{69}$ Here, all contributions of Au NRs to ROS formation enhanced the therapeutic effects of pure TMPyP, resulting in a synergistic effect.

\subsection{Fluorescence measurements on 2D monolayer HNSCC models}

The metal-free bases of porphyrins exhibit intense fluorescence from $600-750 \mathrm{~nm}$ for which deeper tissue penetration of light occurs. In addition, porphyrins can selectively accumulate in tumour tissues to a higher extent than in the surrounding healthy tissues, and be retained there for long periods of time. ${ }^{70}$ This makes them suitable agents for tumour detection and imaging.

To evaluate the optical imaging potential of TMPyP loaded PAA-Au NRs, 2D monolayer A431 cells were incubated with Au, PAA-Au, PAA-Au + TMPyP NRs at $20 \mu \mathrm{g} \mathrm{mL} \mathrm{m}^{-1}$ and equivalent free TMPyP $\left(1.08 \mu \mathrm{g} \mathrm{mL} \mathrm{m}^{-1}\right)$ for $24 \mathrm{~h}$ and the fluorescence emission intensities were recorded at 600-750 $\mathrm{nm}$ under $420 \mathrm{~nm}$ excitation after the cells were washed with PBS to

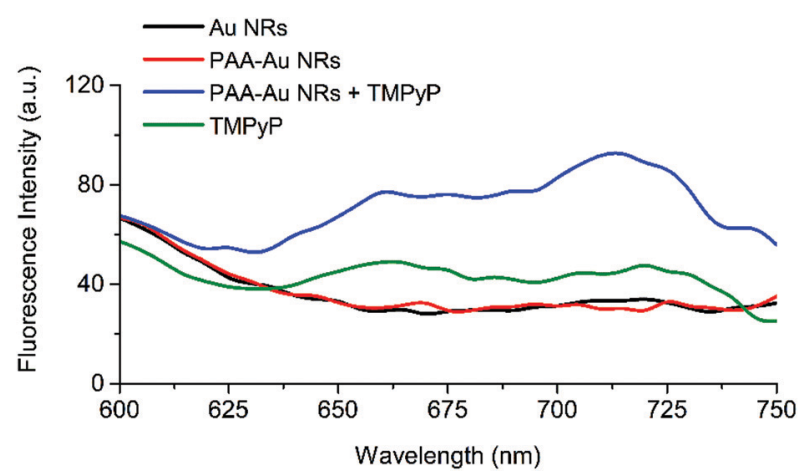

Fig. 3 Fluorescence spectra of 2D monolayer HNSCC models incubated with Au NRs, PAA-Au NRs, TMPyP, PAA-Au NRs + TMPyP NRs at $20 \mu \mathrm{g} \mathrm{mL}^{-1}$ and equivalent free TMPyP $\left(1.08 \mu \mathrm{g} \mathrm{mL}^{-1}\right)$ for $24 \mathrm{~h}\left(\lambda_{\text {exc }}=420 \mathrm{~nm}\right)$. 
A
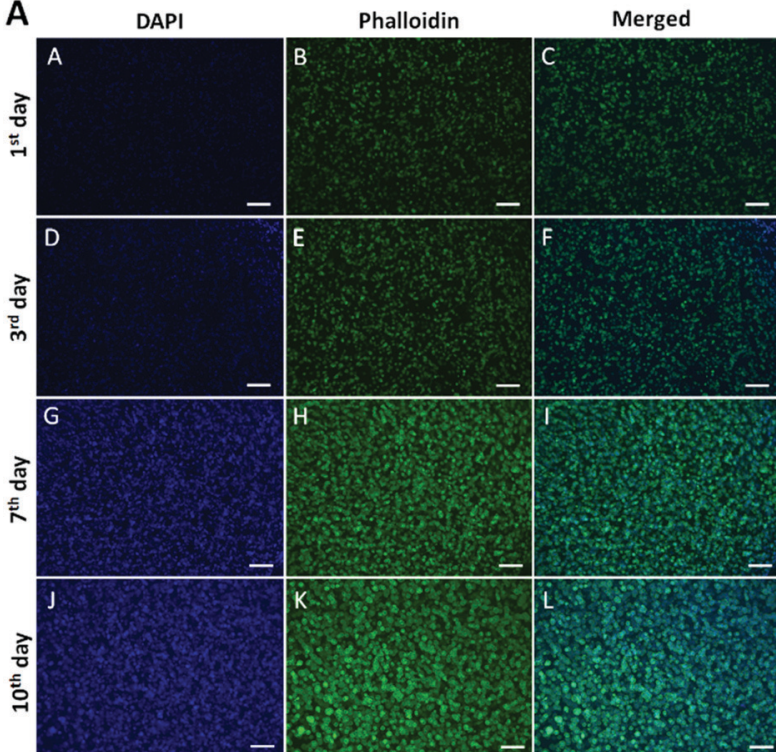

B

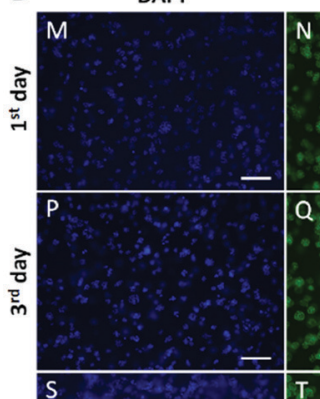

Phalloidin
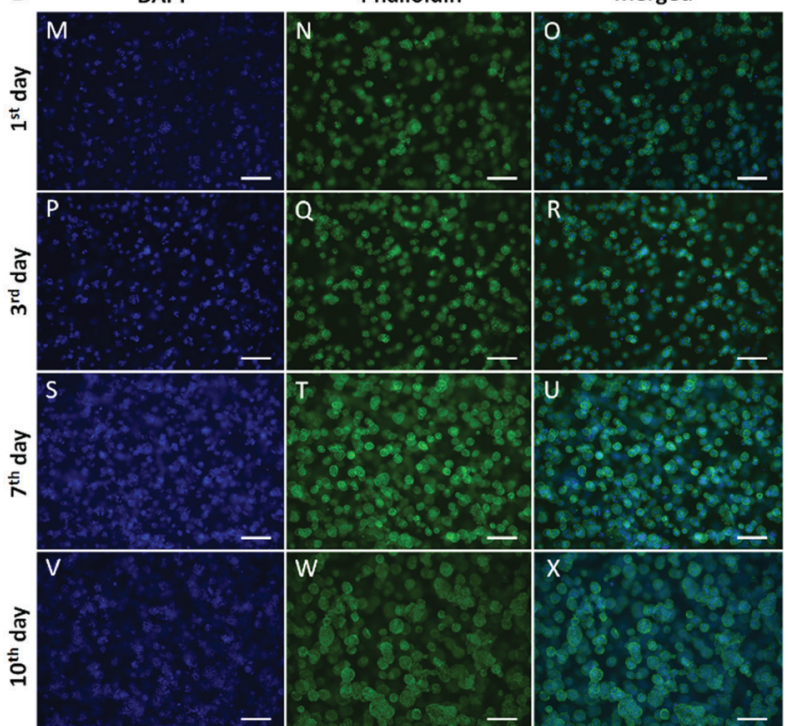

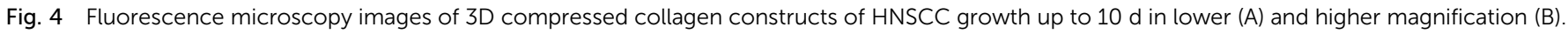

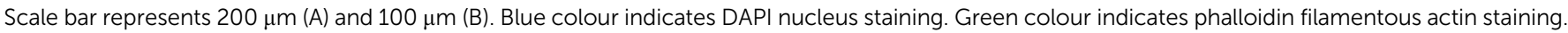

remove uninternalised samples. As can be seen in Fig. 3, Au and PAA-Au NR treated cells do not demonstrate any significant fluorescence feature while cationic porphyrin TMPyP has an obvious emission at 650-750 nm. However, after TMPyP loading, PAA-Au NRs show very strong emission intensity, which is significantly enhanced compared to the fluorescence of free TMPyP in aqueous solution at the equivalent concentration. The concentration dependent fluorescence intensities of the samples in 2D monolayer A431 cells are presented in Fig. S3 (ESI $\dagger$ ). This is probably a result of the increased light absorption of TMPyP with enhanced localized electric field surrounding $\mathrm{Au}$ NRs and as a result of this event, higher emission output, ${ }^{16,23,71,72}$ hence more triplet state and more singlet oxygen generation via the Type 2 process, as seen in the phototoxicity studies shown in Fig. $2 .^{73-76}$ This synergistic effect seen between NRs and the photosensitizer allows their application in optical fluorescence imaging of deep tissues.

\subsection{Manufacture of 3D compressed HNSCC constructs and phototoxicity studies}

In vitro $2 \mathrm{D}$ cell culture and in vivo models have been the main platforms to test materials, especially in drug discovery. ${ }^{24}$ Easy preparation, maintanance and monitoring of 2D cell cultures make them the most applied techniques. However, growing the cells on a flat surface as monolayers without any vital interactions between the cells and surrounding extracellular matrix, and limited cell-to-cell interactions can prevent obtaining real results that can be found in vivo.

The ECM consists of many structural proteins; predominantly, type 1 collagen fibrils is the main constituent of in vivo connective tissues and solid tumours. ${ }^{77-79}$ Therefore, 3D models
A

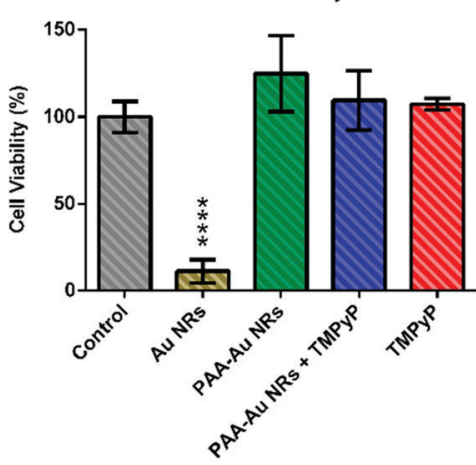

B

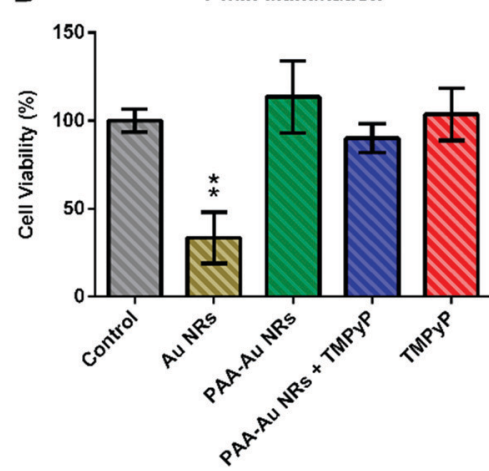

C

20 min illumination

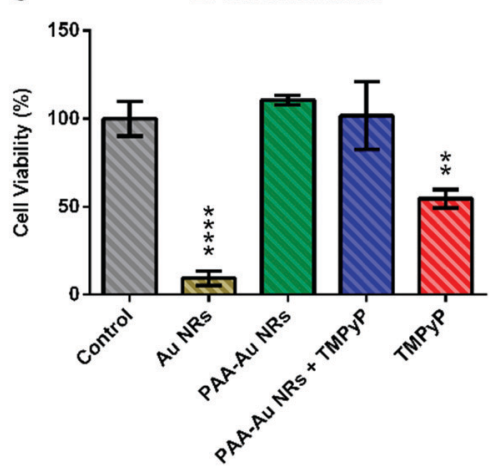

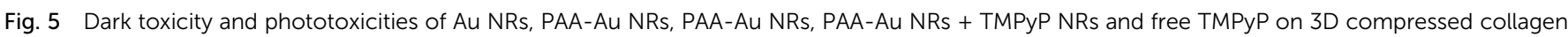

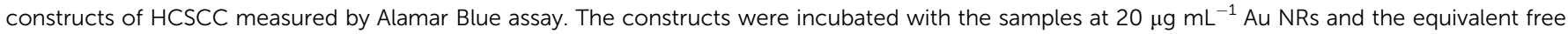

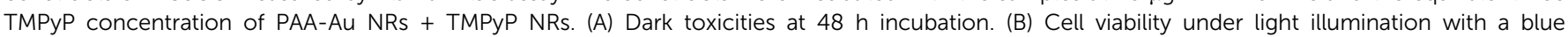

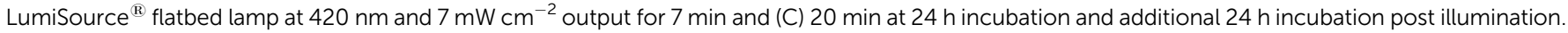


consisting of collagen (type 1) are ideal models to evaluate the biological effects of drugs and biomaterials, mimicking tumour growth within its local environment and characteristics happening in vivo. ${ }^{80}$ Here, to test the dark toxicity and phototoxicity of the prepared photosensitizer loaded Au NRs, we developed 3D compressed collagen constructs of HNSCC. First, we monitored the cancer growth in the constructs up to $10 \mathrm{~d}$ at certain time points, such as the 1st, 3rd, 7th and 10th day. To visualize the cells in the construct, we stained them with the DAPI nucleic dye and phalloidin filamentous actin dye. As can be seen in Fig. 4, the images demonstrate that the cells represent very well the growing profile in the construct and start to form small spheroids even at short times. Based on these results, we decided to use the earliest model of $3 \mathrm{D}$ compressed collagen constructs growth for $1 \mathrm{~d}$.

To understand the dark toxicity and phototoxicity of Au NRs, PAA-Au NRs, PAA-Au NRs + TMPyP NRs and free TMPyP on 3D compressed collagen constructs, the samples were first introduced to the constructs and incubated for $24 \mathrm{~h}$. Then, the media were refreshed and the $3 \mathrm{D}$ constructs were exposed to light illumination for $7 \mathrm{~min}$ and $20 \mathrm{~min}$ for photodynamic therapy or remained without illumination to assess the dark toxicity of the samples. Fig. 5 shows that Au NRs exhibit high dark toxicity, as shown in the 2D dark toxicity data in Fig. 2A. However after PAA coating, the dark toxicity is abrogated and the cell viability increase is comparable to that observed for

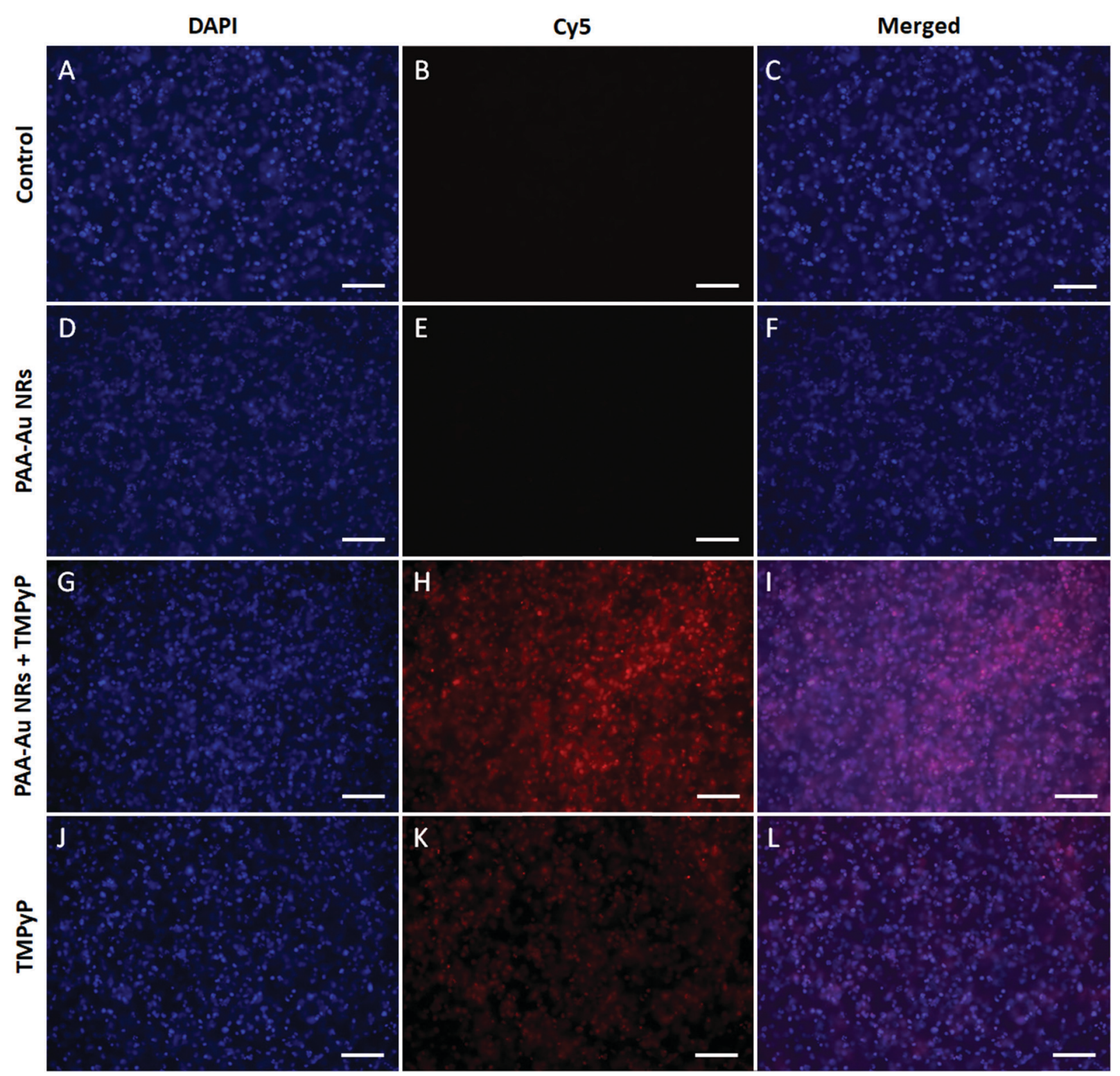

Fig. 6 Fluorescence microscopy images of 3D compressed collagen constructs of HNSCC. Untreated control constructs (A)-(C) and treated constructs with PAA-Au NRs (D)-(F) and PAA-Au NRs + TMPyP NRs (G)-(I) at $20 \mu \mathrm{g} \mathrm{mL} \mathrm{L}^{-1}$ Au NR concentration. Free TMPyP at the equivalent concentration (J)-(L). Blue colour indicates DAPI nucleus staining. Red colour originates from TMPyP emission. Scale bar is $100 \mu \mathrm{m}$. 
controls that were not incubated with the NRs. Free TMPyP and TMPyP loaded PAA-Au NRs exhibit high cell viability when no light illumination was applied. In the case of light illumination for $7 \mathrm{~min}$, the cell viability of PAA-Au NRs and PAA-Au NRs + TMPyP decreased slightly as compared to free TMPyP. When the illumination time was longer, the phototoxicity of PAA-Au NRs and PAA-Au NRs + TMPyP did not show any significant change while the phototoxicity of TMPyP increased.

This could be explained by the limited diffusion of the $\mathrm{Au}$ NRs within the 3D collagen microenvironment. Because of the size of the Au NRs, which are larger than free TMPyP, they have a slower diffusion rate, and the photodynamic effects of the structures are limited in the $3 \mathrm{D}$ cancer environment. ${ }^{32}$

\subsection{Fluorescence imaging of $3 \mathrm{D}$ constructs using cationic porphyrin loaded Au NRs}

The fluorescence images of 3D compressed collagen constructs of HNSCC treated with samples for $24 \mathrm{~h}$ were recorded using an inverted fluorescence microscope using filter sets for DAPI nucleic staining and Cy5 for TMPyP. Due to the high toxicity of the Au NRs, in this case, we used only PAA-Au NRs, PAA-Au NRs + TMPyP and free TMPyP at equivalent concentrations. The experiments were repeated with 2D monolayer structures, however the signal intensity was too low to obtain clear images (data not shown). The images shown in Fig. 6 clearly represent the enhanced fluorescence intensity and efficient cell internalization of TMPyP after being loaded with PAA-Au NRs, as seen in Fig. 3, whereas PAA-Au NRs and control cells do not show any emission. This strong synergistic effect between PAA-Au NRs and TMPyP enables their application as an optical imaging agent for cancer imaging as well as their photodynamic effects.

\section{Conclusions}

In this study, we synthesized Au NRs with an anionic polymer coating and loaded them with a cationic porphyrin photosensitizer, TMPyP, for photodynamic therapy and fluorescence imaging of HNSCC in $2 \mathrm{D}$ and $3 \mathrm{D}$ in vitro cancer models. We showed that coating the NRs with anionic PAA not only conferred biocompatibility and low toxicity but also enabled efficient loading of a cationic photosensitiser to form a nanocomposite delivery system. The results showed that the loading of TMPyP to $\mathrm{Au}$ NRs enhances the absorbance and emission intensity of the photosynthesizer and improves the ROS generation by light irradiation under in vitro cell culture conditions. For short-term illumination, TMPyP loaded NRs showed significantly higher phototoxicity compared to free photosensitizer at equivalent concentrations. Another important result is that $\mathrm{Au}$ NRs are also themselves capable of inducing a small degree of phototoxicity. In addition, 3D compressed collagen constructs incubated with the samples showed very strong fluorescence emission in the red region of the optical spectrum with TMPyP incorporated Au NRs that highlights the utility of 3D models as a biomimetic model for in vivo conditions. The results show that $\mathrm{Au}$ NRs loaded with
TMPyP are promising agents for photodynamic therapy and fluorescence imaging of HNSCC.

\section{Conflicts of interest}

There are no conflicts to declare.

\section{Acknowledgements}

Fatma Demir Duman was supported by the 2219-International Postdoctoral Research Fellowship Program of The Scientific and Technological Research Council of Turkey. Matej Sebek was funded by UCL-A ${ }^{*}$ STAR Singapore PhD program. N. T. K. Thanh thanks EPSRC for funding (EP/M015157/1). The study was also supported by The Mo Keshtgar Memorial Fund administered by the Royal Free Hospital Charity.

\section{References}

1 A. Dylawerska, W. Barczak, A. Wegner, W. Golusinski and W. M. Suchorska, Med. Oncol., 2017, 34, 197.

2 C. R. Leemans, B. J. Braakhuis and R. H. Brakenhoff, Nat. Rev. Cancer, 2011, 11, 9.

3 J. Ferlay, I. Soerjomataram, R. Dikshit, S. Eser, C. Mathers, M. Rebelo, D. M. Parkin, D. Forman and F. Bray, Int. J. Cancer, 2015, 136, E359-E386.

4 R. Siegel, E. Ward, O. Brawley and A. Jemal, Ca-Cancer J. Clin., 2011, 61, 212-236.

5 G. K. Haines, Head \& Neck Cancer: Current Perspectives, Advances, and Challenges, Springer, 2013, pp. 257-287.

6 J. A. Bonner, P. M. Harari, J. Giralt, N. Azarnia, D. M. Shin, R. B. Cohen, C. U. Jones, R. Sur, D. Raben and J. Jassem, N. Engl. J. Med., 2006, 354, 567-578.

7 K. A. Saleh, R. Safwat, A. Bedair, M. El-Sherify, J. Shete and A. A. Basmy, J. Clin. Oncol., 2014, 32, e17044.

8 M. A. Biel, Photochem. Photobiol., 2007, 83, 1063-1068.

9 N. R. Rigual, K. Thankappan, M. Cooper, M. A. Sullivan, T. Dougherty, S. R. Popat, T. R. Loree, M. A. Biel and B. Henderson, Arch. Otolaryngol., Head Neck Surg., 2009, 135, 784-788.

10 S. A. de Visscher, L. J. Melchers, P. U. Dijkstra, B. Karakullukcu, I. B. Tan, C. Hopper, J. L. Roodenburg and M. J. Witjes, Ann. Surg. Oncol., 2013, 20, 3076-3082.

11 H. Ikeda, T. Tobita, S. Ohba, M. Uehara and I. Asahina, Photodiagn. Photodyn. Ther., 2013, 10, 229-235.

12 B. W. Henderson, T. M. Busch and J. W. Snyder, Lasers Surg. Med., 2006, 38, 489-493.

13 B. W. Henderson, S. O. Gollnick, J. W. Snyder, T. M. Busch, P. C. Kousis, R. T. Cheney and J. Morgan, Cancer Res., 2004, 64, 2120-2126.

14 T. M. Busch, H.-W. Wang, E. P. Wileyto, G. Yu and R. M. Bunte, Radiat. Res., 2010, 174, 331-340.

15 E. Yaghini, F. Giuntini, I. M. Eggleston, K. Suhling, A. M. Seifalian and A. J. MacRobert, Small, 2014, 10, 782-792. 
16 Y. Zhang, K. Aslan, M. J. Previte and C. D. Geddes, J. Fluoresc., 2007, 17, 345-349.

17 R. Toftegaard, J. Arnbjerg, K. Daasbjerg, P. R. Ogilby, A. Dmitriev, D. S. Sutherland and L. Poulsen, Angew. Chem., Int. Ed., 2008, 47, 6025-6027.

18 J. Karolin and C. D. Geddes, Phys. Chem. Chem. Phys., 2013, 15, 15740-15745.

19 Y. Zhang, K. Aslan, M. J. Previte, S. N. Malyn and C. D. Geddes, J. Phys. Chem. B, 2006, 110, 25108-25114.

20 B. Jang, J.-Y. Park, C.-H. Tung, I.-H. Kim and Y. Choi, ACS Nano, 2011, 5, 1086-1094.

21 T. Zhao, X. Shen, L. Li, Z. Guan, N. Gao, P. Yuan, S. Q. Yao, Q.-H. Xu and G. Q. Xu, Nanoscale, 2012, 4, 7712-7719.

22 J.-H. Wang, B. Wang, Q. Liu, Q. Li, H. Huang, L. Song, T.-Y. Sun, H. Wang, X.-F. Yu and C. Li, Biomaterials, 2013, 34, 4274-4283.

23 D. C. Ferreira, C. S. Monteiro, C. R. Chaves, G. A. Sáfar, R. L. Moreira, M. V. Pinheiro, D. C. Martins, L. O. Ladeira and K. Krambrock, Colloids Surf., B, 2017, 150, 297-307.

24 A. Nyga, M. Loizidou, M. Emberton and U. Cheema, Acta Biomater., 2013, 9, 7917-7926.

25 H. Kim, Y. Phung and M. Ho, PLoS One, 2012, 7, e39556.

26 E. T. Verjans, J. Doijen, W. Luyten, B. Landuyt and L. Schoofs, J. Cell. Physiol., 2018, 233, 2993-3003.

27 S. Breslin and L. O'Driscoll, Drug Discovery Today, 2013, 18, 240-249.

28 M. Ravi, V. Paramesh, S. Kaviya, E. Anuradha and F. P. Solomon, J. Cell. Physiol., 2015, 230, 16-26.

29 K. P. Ricketts, U. Cheema, A. Nyga, A. Castoldi, C. Guazzoni, T. Magdeldin, M. Emberton, A. P. Gibson, G. J. Royle and M. Loizidou, Small, 2014, 10, 3954-3961.

30 V. López-Dávila, T. Magdeldin, H. Welch, M. V. Dwek, I. Uchegbu and M. Loizidou, Nanomedicine, 2016, 11, 331-344.

31 L. Mohammad-Hadi, A. J. MacRobert, M. Loizidou and E. Yaghini, Nanoscale, 2018, 10, 1570-1581.

32 L. M. Hadi, E. Yaghini, K. Stamati, M. Loizidou and A. J. MacRobert, Acta Biomater., 2018, 81, 80-92.

33 S. Pushpan, S. Venkatraman, V. Anand, J. Sankar, D. Parmeswaran, S. Ganesan and T. Chandrashekar, Curr. Med. Chem.: Anti-Cancer Agents, 2002, 2, 187-207.

34 A. Garcia-Sampedro, A. Tabero, I. Mahamed and P. Acedo, J. Porphyrins phthalocyanines, 2019, 23, 11-27.

35 S. Tada-Oikawa, S. Oikawa, J. Hirayama, K. Hirakawa and S. Kawanishi, Photochem. Photobiol., 2009, 85, 1391-1399.

36 V. Cenklová, J. Photochem. Photobiol., B, 2017, 173, 522-537.

37 D. Sengupta, Z. H. Mazumdar, A. Mukherjee, D. Sharma, A. K. Halder, S. Basu and T. Jha, J. Photochem. Photobiol., B, 2018, 178, 228-236.

38 I. A. Patito, C. Rothmann and Z. Malik, Biol. Cell, 2001, 93, 285-291.

39 G. Siboni, I. Amit-Patito, E. Weizman, M. Waintraub-Porat, H. Weitman, B. Ehrenberg and Z. Malik, Cancer Lett., 2003, 196, 57-64.

40 A. Juarranz, A. Villanueva, V. Diaz and M. Canete, J. Photochem. Photobiol., B, 1995, 27, 47-53.
41 K. Pizova, R. Bajgar, R. Fillerova, E. Kriegova, V. Cenklova, K. Langova, P. Konecny and H. Kolarova, J. Photochem. Photobiol., B, 2015, 142, 186-196.

42 V. Carvalho, C. Melo, V. S. Bagnato and J. R. Perussi, Laser Phys., 2002, 12, 1314-1319.

43 A. R. Monteiro, C. I. Ramos, S. Fateixa, N. M. Moura, M. G. Neves and T. Trindade, ACS Omega, 2018, 3, 11184-11191.

44 F. Cheng, X. Wu, M. Liu, Y. Lon, G. Chen and R. Zeng, Sens. Actuators, B, 2016, 228, 673-678.

45 X. Wang, J. Min, W. Wang, Y. Wang, G. Yin and R. Wang, Analyst, 2018, 143, 2641-2647.

46 X.-a. Zhang, K. S. Lovejoy, A. Jasanoff and S. J. Lippard, Proc. Natl. Acad. Sci. U. S. A., 2007, 104, 10780-10785.

47 R. M. Pallares, Y. Wang, S. H. Lim, N. n. T. K. Thanh and X. Su, Nanomedicine, 2016, 11, 2845-2860.

48 R. M. Pallares, M. Bosman, N. T. Thanh and X. Su, Nanoscale, 2016, 8, 19973-19977.

49 A. M. Alkilany, P. K. Nagaria, C. R. Hexel, T. J. Shaw, C. J. Murphy and M. D. Wyatt, Small, 2009, 5, 701-708.

50 T. Magdeldin, V. López-Dávila, C. Villemant, G. Cameron, R. Drake, U. Cheema and M. Loizidou, J. Tissue Eng., 2014, 5, 2041731414544183.

51 T. Magdeldin, V. López-Dávila, J. Pape, G. W. Cameron, M. Emberton, M. Loizidou and U. Cheema, Sci. Rep., 2017, 7, 44045.

52 S. Nie, Y. Xing, G. J. Kim and J. W. Simons, Annu. Rev. Biomed. Eng., 2007, 9, 257-288.

53 M. E. Davis, Z. Chen and D. M. Shin, Nanoscience And Technology: A Collection of Reviews from Nature Journals, World Scientific, 2010, pp. 239-250.

54 N. Nishiyama, S. Okazaki, H. Cabral, M. Miyamoto, Y. Kato, Y. Sugiyama, K. Nishio, Y. Matsumura and K. Kataoka, Cancer Res., 2003, 63, 8977-8983.

55 A. Srivatsan, J. R. Missert, S. K. Upadhyay and R. K. Pandey, J. Porphyrins phthalocyanines, 2015, 19, 109-134.

56 B. Nikoobakht and M. A. El-Sayed, Chem. Mater., 2003, 15, 1957-1962.

57 I. P. Lau, H. Chen, J. Wang, H. C. Ong, K. C.-F. Leung, H. P. Ho and S. K. Kong, Nanotoxicology, 2012, 6, 847-856.

58 H. Zhu, Y. Chen, F.-J. Yan, J. Chen, X.-F. Tao, J. Ling, B. Yang, Q.-J. He and Z.-W. Mao, Acta Biomater., 2017, 50, 534-545.

59 R. M. Pallares, X. Su, S. H. Lim and N. T. Thanh, J. Mater. Chem. C, 2016, 4, 53-61.

60 D. Li, Y. J. Jang, J. Lee, J.-E. Lee, S. T. Kochuveedu and D. H. Kim, J. Mater. Chem., 2011, 21, 16453-16460.

61 W. Zhang, J. Meng, Y. Ji, X. Li, H. Kong, X. Wu and H. Xu, Nanoscale, 2011, 3, 3923-3932.

62 X. Gong, T. Milic, C. Xu, J. D. Batteas and C. M. Drain, J. Am. Chem. Soc., 2002, 124, 14290-14291.

63 U. SeokáChung, Chem. Commun., 2016, 52, 1258-1261.

64 M. Nowostawska, S. A. Corr, S. J. Byrne, J. Conroy, Y. Volkov and Y. K. Gun'ko, J. Nanobiotechnol., 2011, 9, 13.

65 L. Zhang, H. Chen, J. Wang, Y. F. Li, J. Wang, Y. Sang, S. J. Xiao, L. Zhan and C. Z. Huang, Small, 2010, 6, 2001-2009. 
66 M. Ethirajan, Y. Chen, P. Joshi and R. K. Pandey, Chem. Soc. Rev., 2011, 40, 340-362.

67 Y. Zhou, X. Liang and Z. Dai, Nanoscale, 2016, 8, 12394-12405.

68 Y. Qiu, Y. Liu, L. Wang, L. Xu, R. Bai, Y. Ji, X. Wu, Y. Zhao, Y. Li and C. Chen, Biomaterials, 2010, 31, 7606-7619.

69 F. Rossi, E. H. Khoo, X. Su and N. T. K. Thanh, ACS Appl. Bio Mater., 2019, 3, 315-326.

70 M. Vicente, Curr. Med. Chem.: Anti-Cancer Agents, 2001, 1, 175-194.

71 T. Zhao, K. Yu, L. Li, T. Zhang, Z. Guan, N. Gao, P. Yuan, S. Li, S. Q. Yao and Q.-H. Xu, ACS Appl. Mater. Interfaces, 2014, 6, 2700-2708.

72 X. Huang, X.-J. Tian, W.-l. Yang, B. Ehrenberg and J.-Y. Chen, Phys. Chem. Chem. Phys., 2013, 15, 15727-15733.
73 J. Kou, D. Dou and L. Yang, Oncotarget, 2017, 8, 81591.

74 F. Cieplik, L. Tabenski, W. Buchalla and T. Maisch, Front. Microbiol., 2014, 5, 405.

75 R. Baskaran, J. Lee and S.-G. Yang, Biomater. Res., 2018, 22, 1-8.

76 E. G. Owusu, A. J. MacRobert, I. Naasani, I. P. Parkin, E. Allan and E. Yaghini, ACS Appl. Mater. Interfaces, 2019, 11, 12367-12378.

77 R. Edmondson, J. J. Broglie, A. F. Adcock and L. Yang, Assay Drug Dev. Technol., 2014, 12, 207-218.

78 K. M. Yamada and E. Cukierman, Cell, 2007, 130, 601-610.

79 M. Alemany-Ribes, M. García-Díaz, M. Busom, S. Nonell and C. E. Semino, Tissue Eng., Part A, 2013, 19, 1665-1674.

80 D. Antoni, H. Burckel, E. Josset and G. Noel, Int. J. Mol. Sci., 2015, 16, 5517-5527. 